\title{
sciendo
}

Current Issues in Pharmacy and Medical Sciences

Formerly ANNALES UNIVERSITATIS MARIAE CURIE-SKLODOWSKA, SECTIO DDD, PHARMACIA

journal homepage: http://www.curipms.umlub.pl/

\section{Platelet indices as potential biomarkers for determining active ulcerative colitis and assessing the efficacy of biological treatment - experience of a single centre - a pilot study}

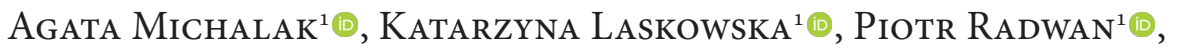

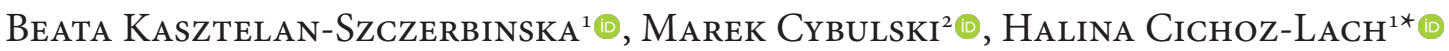 \\ ${ }^{1}$ Department of Gastroenterology with Endoscopy Unit, Medical University of Lublin, Jaczewskiego 8, 20-090 Lublin, Poland \\ 2 Department of Biochemistry and Molecular Biology, Medical University of Lublin, Chodzki 1, 20-093 Lublin, Poland
}

\begin{tabular}{l}
\hline ARTICLE INFO \\
\hline Received 06 March 2019 \\
Accepted 03 April 2019
\end{tabular}

Keywords: infliximab, platelet indices, ulcerative colitis.

\begin{abstract}
Various laboratory parameters are commonly used to assess the efficacy of biological treatment (BT). The aim of our study was to assess the correlation between platelet (PLT) indices: (mean platelet volume (MPV), plateletcrit (PCT), platelet distribution width $(\mathrm{PDW})$ ), C-reactive protein (CRP) and endoscopic picture in the course of infliximab induction regimen in ulcerative colitis (UC) patients. The study enrolled 46 patients with UC - 32 men and 16 women. They were administered infliximab (standard induction therapy). Laboratory tests (CRP and PLT indices) and colonoscopy were performed in all patients during the induction regimen - at 0,2 , and 6 weeks and in follow-up six weeks after the completion of induction therapy. The study revealed a statistically significant decrease in CRP and PLT, and an increase in MPV, together with improvement of endoscopic picture ( $p$ <0.001) (MAYO score, MAYO endoscopic subscore) in all patients. PCT and PDW values remained in normal ranges before BT and after the finish of the induction regimen. PCT correlated positively with CRP before the introduction of BT $(p=0.018)$. In addition, positive correlations between PCT and PLT count were noticed before infliximab induction regimen and in follow-up after the finished of therapy $(\mathrm{p}<0.001)$. Additionally, a negative correlation between PLT count and MPV prior to the first dose of infliximab was observed ( $\mathrm{p}=0.032$ ). Our data suggest that PLT indices could be useful biomarkers for determining active UC and for assessing the efficacy of BT. From what we know, this is the first survey devoted to PLT parameters in Polish patients with UC.
\end{abstract}

\section{INTRODUCTION}

Inflammatory bowel disease (IBD), represented by Crohn's disease (CD) and ulcerative colitis (UC), is a composed disorder affecting mainly the gastrointestinal tract. IBD pathogenesis is multifactorial, however, the immune system, together with genetic and environmental backgrounds are mostly implicated. There is also a growing body of evidence suggesting a causative role of non-immune cells like endothelial, mesenchymal, nerve cells and platelets (PLT) in a IBD inflammatory cascade. PLT abnormalities are known to participate in the pathological appearance of IBD, nevertheless, the existing knowledge concerning this field is rather weak. On the other hand, a lot of studies underscore

\footnotetext{
* Corresponding author

e-mail: lach.halina@wp.pl
}

the potent proinflammatory features of PLT, barring their role in hemostasis. Among potential PLT alterations, it is worth highlighting morphological changes [mean PLT volume (MPV), PLT distribution width (PDW), plateletcrit (PCT), augmented granular content], count increase, microparticles release, overexcretion of granular content, and increased formation of PLT-PLT and PLT-leukocyte aggregates, which are all inseparably connected with PLT activation induced by inflammatory agonists [1,2]. MPV is a precise measure of platelet size, obtained via electrical impedance using automated hematological analyzers. PDW is an index of platelet volume heterogeneity and may increase in platelet activation. PCT is the volume occupied by platelets in the blood, counted as a percentage $(\mathrm{PCT}=$ PLT count $\times$ MPV/10) [3]. The aim of this study was to 
assess the correlation between PLT indices: MPV, PCT, PDW and the severity of inflammatory process [PLT count, C-reactive protein (CRP) level and endoscopic picture] in the course of infliximab (IFX) induction regimen in UC patients.

\section{MATERIALS AND METHODS}

Local ethics committee ruled that no formal ethics approval was required in this study, however, written consent was obtained from each participant of the study. The patients signed informed consent forms and agreed to present their laboratory results. The study enrolled 46 patients with diagnosed UC - 32 men and 16 women, respectively. UC diagnosis was based on commonly used criteria. Patients were administered IFX intravenously $(5 \mathrm{mg} / \mathrm{kg}$; an induction regimen of 3 doses at 0, 2 and 6 weeks). Laboratory tests (CRP and PLT indices) and colonoscopy were performed in all patients during the induction regimen - at 0,2 , and 6 weeks and, in follow-up, six weeks after the completion of induction therapy. To assess the severity of inflammatory process in the course of BT, CRP (a normal range $0-5 \mathrm{mg} / \mathrm{L}$ ), PLT count (a normal range 150-400 $\times 109 / \mathrm{L}$ ) and PLT indices [MPV (a normal range 8-11 fl), PCT (a normal range $0.12-0.3 \%$ ), PDW (a normal range 40-60 \%) were measured in all participants. To assess endoscopic picture of the disease, Mayo score was also calculated, with special attention put towards endoscopic subscore. All participants were unresponsive to 5-aminosalicylates, immunonodulators and corticosteroids and finally switched to IFX; they continued previous pharmacotherapies during biological treatment (BT). Patients were tested for tuberculosis, cytomegalovirus, Epstein-Barr virus, human immunodeficiency virus, hepatitis $\mathrm{C}$ virus, and hepatitis $\mathrm{B}$ virus prior to the initiation of BT. Performed tests excluded infections in all participants. Calculations and statistical analysis of obtained data were performed with Statistica 12 Software. Spearman's rank correlation ( $\mathrm{R}$ - Spearman's correlation test) and analysis of variance (ANOVA) were used to assess the dependencies between laboratory tests results and endoscopic picture. A p-value of less than 0.05 was considered significant.

\section{RESULTS}

Demographic characteristic, results of laboratory tests and endoscopic procedures in examined patients, together with statistical analysis are presented in Table 1.

The study revealed a statistically significant decrease in CRP and PLT and an increase in MPV, together with improvement of endoscopic picture (MAYO score, MAYO endoscopic subscore) in all patients six weeks after finishing the IFX induction regimen. Furthermore, CRP level decreased from 32.35 to $7.05 \mathrm{mg} / \mathrm{L}$, without achieving a normal range. In contrast, MPV value was too low before the introduction of BT and did not normalize after IFX induction regimen either. In addition, PLT count remained in a normal range before and after finished BT. Similarly, PCT and PDW were in a normal range in all stages of the study. Subsequently, PCT correlated positively with both CRP and PLT count before the introduction of BT. We also found
Table 1. Demographic characteristics and results of laboratory tests and MAYO scale in examined UC patients

\begin{tabular}{|c|c|c|c|}
\hline & Parameter & $\begin{array}{l}\text { UC patients } \\
n=46\end{array}$ & $\mathrm{p}$ value \\
\hline & Age (years) & $38.8(14.38)$ & \\
\hline & Gender (females/males) & $31 / 15$ & \\
\hline \multirow{4}{*}{$\begin{array}{l}\text { C-reactive protein } \\
{[0-5 \mathrm{mg} / \mathrm{L}]}\end{array}$} & prior to the first dose & $32.35(48.14)$ & \multirow{4}{*}{$<0.001^{*}$} \\
\hline & prior to the second dose & $5.02(8.96)$ & \\
\hline & prior to the third dose & $6.12(11.15)$ & \\
\hline & $\begin{array}{l}6 \text { weeks after finished } \\
\text { infliximab induction regimen }\end{array}$ & $7.05(11.6)$ & \\
\hline \multirow{4}{*}{$\begin{array}{l}\text { Platelet count } \\
{[150-400 \times 109 / \mathrm{L}]}\end{array}$} & prior to the first dose & $398(148.41)$ & \multirow{4}{*}{$<0.001 *$} \\
\hline & prior to the second dose & $324(112.05)$ & \\
\hline & prior to the third dose & $304(99.03)$ & \\
\hline & \begin{tabular}{|l|}
6 weeks after completing \\
infliximab induction regimen
\end{tabular} & $315(87.5)$ & \\
\hline \multirow{4}{*}{$\begin{array}{l}\text { Mean platelet } \\
\text { volume } \\
{[8-11 \mathrm{fl}]}\end{array}$} & prior to the first dose & $6.72(0.85)$ & \multirow{4}{*}{$<0.001^{*}$} \\
\hline & prior to the second dose & $7.01(0.76)$ & \\
\hline & prior to the third dose & $7.19(0.94)$ & \\
\hline & $\begin{array}{l}6 \text { weeks after completing } \\
\text { infliximab induction regimen }\end{array}$ & $7.23(0.84)$ & \\
\hline \multirow{4}{*}{$\begin{array}{l}\text { Plateletcrit } \\
{[0.12-0.3 \%]}\end{array}$} & prior to the first dose & $0.26(0.09)$ & \multirow{4}{*}{$<0.001^{*}$} \\
\hline & prior to the second dose & $0.23(0.08)$ & \\
\hline & prior to the third dose & $0.22(0.06)$ & \\
\hline & $\begin{array}{l}6 \text { weeks after completing } \\
\text { infliximab induction regimen }\end{array}$ & $0.22(0.06)$ & \\
\hline \multirow{4}{*}{$\begin{array}{l}\text { Platelet } \\
\text { distribution width } \\
{[40-60 \%]}\end{array}$} & prior to the first dose & $46.63(6.87)$ & \multirow{4}{*}{0.08} \\
\hline & prior to the second dose & $47.1(6.35)$ & \\
\hline & prior to the third dose & $47.32(6.55)$ & \\
\hline & $\begin{array}{l}6 \text { weeks after completing } \\
\text { infliximab induction regimen }\end{array}$ & $49.02(6.95)$ & \\
\hline \multirow{4}{*}{$\begin{array}{l}\text { MAYO score } \\
{[0-12]}\end{array}$} & prior to the first dose & $10(1.72)$ & \multirow{4}{*}{$<0.001^{*}$} \\
\hline & prior to the second dose & $6(2.43)$ & \\
\hline & score prior to the third dose & $4(2.11)$ & \\
\hline & $\begin{array}{l}6 \text { weeks after completing } \\
\text { infliximab induction regimen }\end{array}$ & $3(1.67)$ & \\
\hline \multirow{4}{*}{$\begin{array}{l}\text { MAYO endoscopic } \\
\text { subscore } \\
{[0-3]}\end{array}$} & prior to the first dose & $3(0.38)$ & \multirow{4}{*}{$<0.001 *$} \\
\hline & prior to the second dose & $2(0.72)$ & \\
\hline & prior to the third dose & $2(0.77)$ & \\
\hline & $\begin{array}{l}6 \text { weeks after completing } \\
\text { infliximab induction regimen }\end{array}$ & $2(0.88)$ & \\
\hline
\end{tabular}

* - statistically significant differences, $\mathrm{p}<0.05$

Analysis of variance (ANOVA). Data presented as mean values (SD) (standard deviation)

positive correlations between PCT and PLT count before IFX induction regimen and in follow-up after completion of therapy. Additionally, a negative correlation between PLT count and MPV prior to the first dose of IFX was observed. All correlations are presented in Figures 1-3.

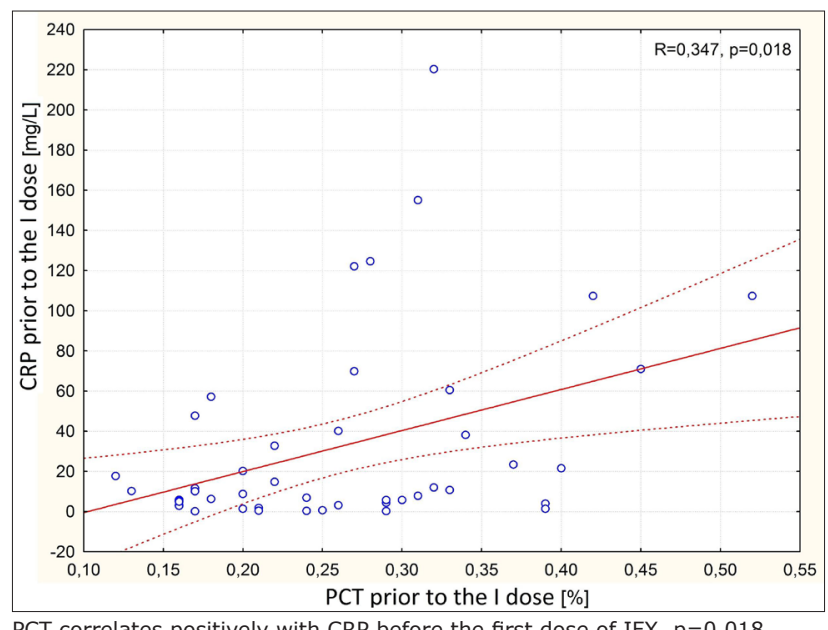

PCT correlates positively with CRP before the first dose of IFX, $p=0.018$

Figure 1. Correlation between PCT and CRP before the first dose of IFX 


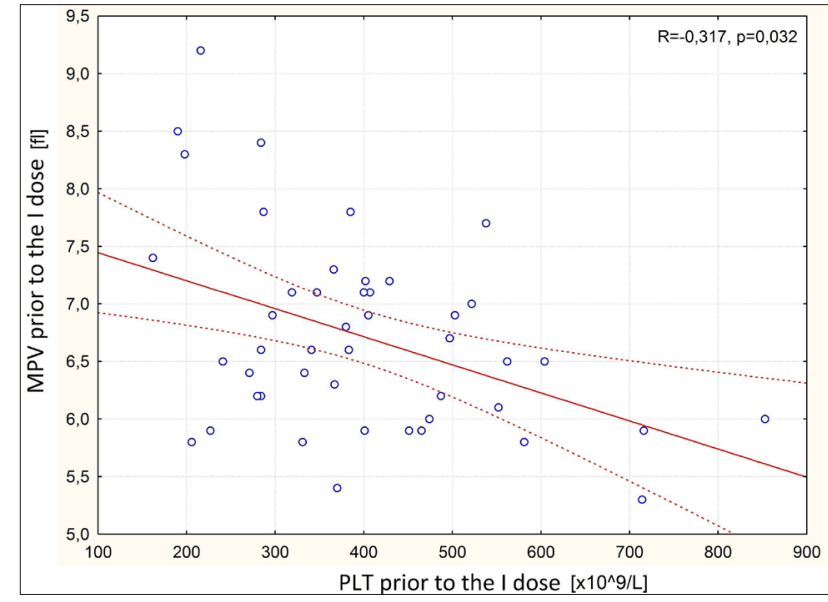

PLT correlates negatively with MPV before the first dose of IFX, $\mathrm{p}=0.032$

Figure 2. Correlation between PLT and MPV before the first dose of IFX
TPO production might be stimulated by proinflammatory factors, especially interleukin 6 (IL-6), which is known as an acute phase reactant. Previous studies have demonstrated that IBD patients with thrombocytosis have elevated plasma TPO and IL-6 levels. Nevertheless, the correlation between PLT number and TPO activation has not been elucidated so far. The most widely-investigated PLT parameter in humans is MPV. PLT volume decreases in the course of inflammatory process, which is mainly caused by thrombopoiesis abnormalities and increased PLT consumption $[4,5]$. Data collected in our investigation support this theory; MPV values correlate negatively with PLT count in our UC patients before the introduction of IFX treatment, thus, we observed an inverse correlation between MPV and disease activity. Furthermore, Sobolewska et al. reported a correlation between increase in MPV and response to IFX
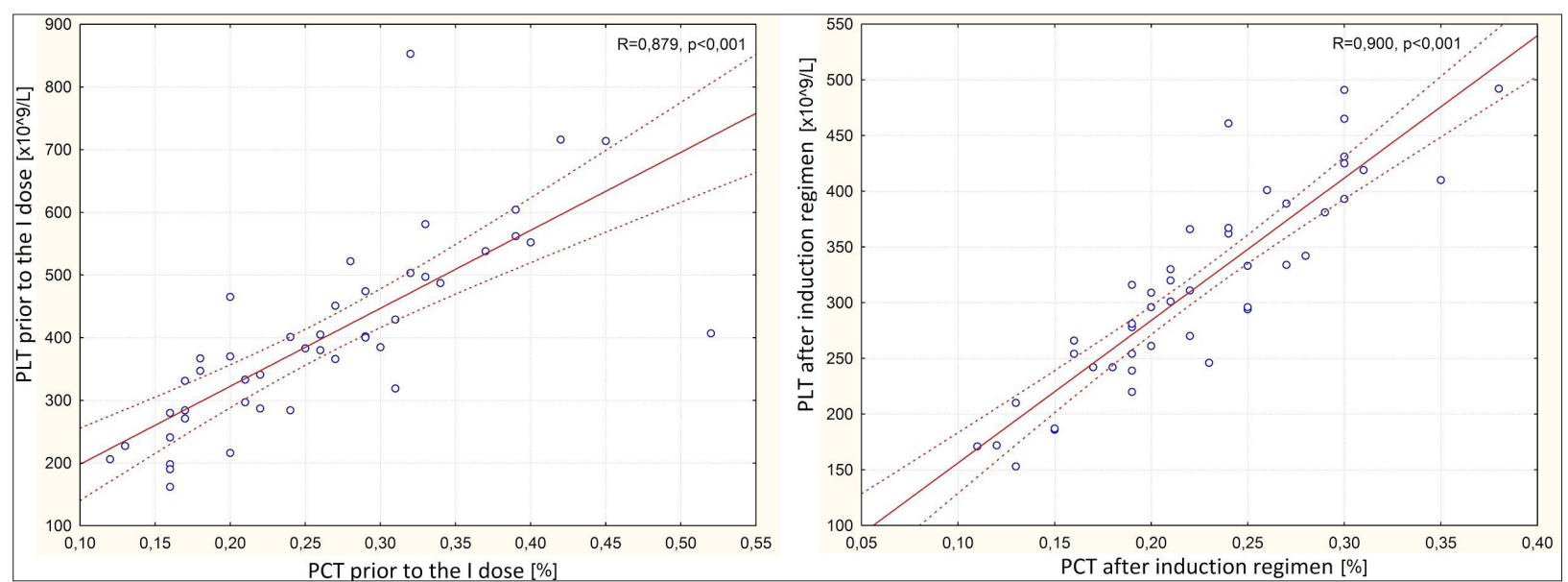

PCT correlates positively with PLT before the first dose of IFX and after completing BT, $p<0.001$

Figure 3. Correlations between PCT and PLT: before the first dose of IFX and after completing BT

\section{DISCUSSION}

The pathological appearance of chronic inflammatory disorders is frequently linked to PLT abnormalities and their morphological changes. An increased concentration of proinflammatory particles stimulates bone marrow to release PLT generation before they finish maturation. This process leads to the accumulation of small amounts of indignificant PLT in circulation and thrombocytosis. Therefore, an increase in PLT count has co-relation to IBD activity indices. Simultaneously, larger and more active PLT are consumed at inflammatory areas in the intestinal microvasculature of IBD patients. As a result, studies conducted on IBD patients reveal decreased MPV values during the active phase of the disease. Additionally, a correlation between MPV and the severity of an exacerbation exists. Thrombopoiesis is mainly controlled by the plasma thrombopoietin (TPO). In normal conditions, plasma TPO binds to C-Mannosylation of the thrombopoietin receptor (C-Mpl) on the PLT surface, and the remaining fraction stimulates thrombopoiesis by binding to the same receptors on progenitor megakaryocytes in bone marrow. Hence, physiologically thrombopoiesis is regulated by a negative feedback mechanism based on PLT mass in blood. Hepatic in CD patients [6]. MPV changes are not exclusively linked to IBD. They correlate with various systemic disorders such as myocardial infarction, rheumatoid arthritis and acute pancreatitis $[7,8]$. PDW and MPV were also reported to be potential prognostic markers in the course of colorectal cancer; elevated MPV was also found to indicate its poor prognosis. Moreover, MPV was shown to serve a role of biomarker for early pancreatic, gastric and hepatocellular carcinoma diagnosis [9-12]. Otzurk et al., for example, found a dependency between infectious conditions and elevation of PLT and PCT levels [13]. Our study demonstrated a positive correlation between PLT count and PCT value prior to IFX treatment and after the completion of the induction regimen. Furthermore, Tang et al. suggested PCT to be a sensitive marker for determining CD activity [14]. In our patients, PCT correlated positively with CRP in acute phase of the disease, before the introduction of BT. Despite the commonness of BT in the course of IBD, we are still unable to define certain values of laboratory parameters to assess precisely the degree of the response to administered agents and to predict the outcome of treatment. Recently, PLT indices have become 
parameters of great importance because of their possible utility in various areas of medicine. In the context of IBD, they should also be explored and introduced into the range of potential indicators of inflammatory state and the response to BT, because the chronic inflammatory process in patients with IBD has connection with elevated PLT count, changes in their activation and in their morphological parameters.

\section{CONCLUSIONS}

Our data suggest that PLT indices could be useful biomarkers for determining active UC and for assessing the efficacy of BT. We believe ours is the first survey devoted to PLT parameters in Polish patients with UC. We realize the limitations of this investigation due to a small number of enrolled participants. However, this study is a pilot study among our patients in this field.

\section{ORCID iDs}

Agata Michalak (1)https://orcid.org/0000-0003-4426-6321

Katarzyna Laskowska (1) https://orcid.org/0000-0001-6767-3929

Piotr Radwan (1) https://orcid.org/0000-0002-5126-0780

Beata Kasztelan-Szczerbińska

(D)https://orcid.org/0000-0002-7198-4428

Marek Cybulski (D)https://orcid.org/0000-0003-0540-1199

Halina Cichoż-Lach (Dhttps://orcid.org/0000-0002-7337-835X

\section{REFERENCES}

1. Voudoukis E, Karmiris K, Koutroubakis IE. Multipotent role of platelets in inflammatory bowel diseases: a clinical approach. World J Gastroenterol. 2014;20:3180-90.

2. Giannotta M, Tapete G, Emmi G, Silvestri E, Milla M. Thrombosis in inflammatory bowel diseases: what's the link? Thromb J. 2015;13:14.
3. Budak YU, Polat M, Huysal K. The use of platelet indices, plateletcrit, mean platelet volume and platelet distribution width in emergency non-traumatic abdominal surgery: a systematic review. Biochem Med (Zagreb) 2016;26:178-93.

4. Ghoshal K, Bhattacharyya M. Overview of platelet physiology: its hemostatic and nonhemostatic role in disease pathogenesis. Scientific World Journal. 2014;2014:781857.

5. Öztürk ZA, Dag MS, Kuyumcu ME, Cam H, Yesil Y, Yilmaz N, et al. Could platelet indices be new biomarkers for inflammatory bowel diseases? Eur Rev Med Pharmacol Sci. 2013;17:334-41.

6. Sobolewska A, Włodarczyk M, Stec-Michalska K, Fichna J, Wiśniewska-Jarosińska M. Mean platelet volume in Crohn's disease patients predicts sustained response to a 52 -week infliximab therapy: a pilot study. Dig Dis Sci. 2016;61:542-9.

7. Lei JJ, Zhou L, Liu Q, Xiong C, Xu CF. Can mean platelet volume play a role in evaluating the severity of acute pancreatitis? World $J$ Gastroenterol. 2017;23:2404-13.

8. Choi DH, Kang SH, Song H. Mean platelet volume: a potential biomarker of the risk and prognosis of heart disease. Korean J Intern Med. 2016;311009-17.

9. Matowicka-Karna J, Kamocki Z, Polińska B, Osaa J, Kemona H. Platelets and inflammatory markers in patients with gastric cancer. Clin Dev Immunol. 2013;2013:401623.

10. Li N, Yu Z, Zhang X, Liu T, Sun YX, Wang RT, et al. Elevated mean platelet volume predicts poor prognosis in colorectal cancer. Sci Rep. 2017;7:10261.

11. Song X, Zhu H, Pei Q, Tan F, Li C, Zhou Z, et al. Significance of inflammation-based indices in the prognosis of patients with nonmetastatic colorectal cancer. Oncotarget. 2017;8:45178-89.

12. Li N, Yu Z, Zhang X, Liu T, Sun YX, Wang RT, et al. Elevated mean platelet volume predicts poor prognosis in colorectal cancer. Scientific Reports. 2017;7:10261.

13. Ozturk N, Baygutalp NK, Bakan E, Altas GF, Polat H, Dorman E. Changes in platelet parameters in leukocytosis. Afr Med J. 2016;24:185.

14. Tang J, Gao X, Zhi M, Zhou HM, Zhang M, Chen HW, et al. Plateletcrit: a sensitive biomarker for evaluating disease activity in Crohn's disease with low hs-CRP. J Dig Dis. 2015;16:118-24. 